UK nuclear power

\section{Next reactor still not decided}

THE public inquiry into the application from the Central Electricity Generating Board (CEGB) to build Britain's first pressurized water reactor (PWR) in Suffolk has now entered its second year, with no prospect of finishing before the autumn. It might easily take a further six to nine months for the Inspector, Sir Frank Layfield, to complete his report and submit it with recommendations to the Secretary of State for the Environment, who will take the final decision on whether the board should be allowed to go ahead.

The inquiry is being held in a former malting-house now converted into a fine concert hall, in the tiny village of Snape in Suffolk. The planned site for the PWR is just a few miles away at Sizewell, near an existing gas-cooled nuclear power station. The inquiry hall could hold 800 spectators, but since early last year it has rarely held more than a handful of people. All the activity takes place on a raised platform where Sir Frank sits, surrounded by crates of documents and under the continual glow of spotlights, attended by two assessors and an assortment of lawyers.

CEGB has a similar posse of lawyers on the platform ready to jump up and introduce procedural points, while the objectors, running their case on a limited budget, have a smaller contingent but manage to keep the words flowing.

A great many words are involved. Every one is taken down in shorthand, and the inquiry's secretariat now estimates that, including supporting documents, it distributes 200,000 sheets of paper a week. The

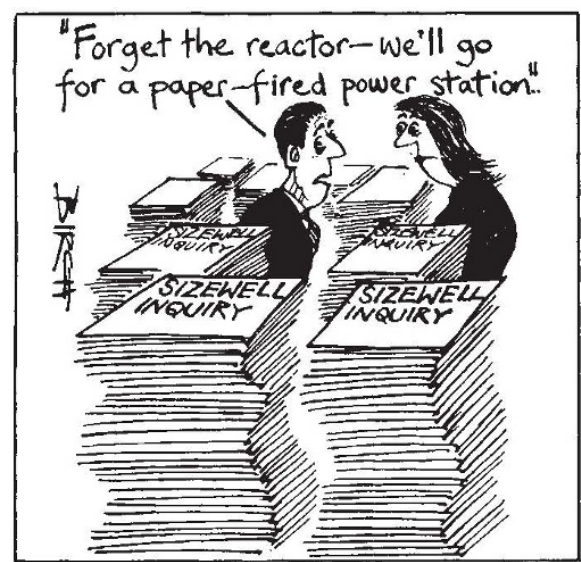

proportion of these that are ever read is a different matter.

Local residents have mixed feelings about the effects of the inquiry on Snape itself, but there can be no doubt that money from CEGB has largely financed the conversion of the concert hall complex into a potentially profitable leisure centre, and that jobs will be created if the new reactor is built. Under the terms of the inquiry, the board pays for everything, from the inspector's salary down to the bus that every day runs to and from the nearest town, Ipswich. More often than not, however, the bus is empty. The one pub in the vicinity appears to be enjoying a good trade from board employees and objectors alike, although one person who is not to be seen in The Plough and Sail is Sir Frank Layfield: protocol demands that he is not seen dining, and presumably drinking, with either party.

The first three months of the inquiry were taken up by the electricity utility reading out its evidence, and were followed by nine months of detailed examination of the economic justification for the board's case. The objectors claim to have significantly weakened it: the board itself admits to having refined some of its assumptions but insists the case holds. Now, attention has turned to safety aspects.

Friends of the Earth, the British environmental group, has hired a barrister to make its case that the board's design is not acceptably safe, and reckons to have spent $£ 100,000$ on the inquiry so far. The group will retire from the inquiry in a few weeks' time, to be replaced by the Stop Sizewell B Association, which will concentrate on attacking the board's operational safety claims. In particular, the association will be pressing that the design should include electromagnetic filters in the reactor's coolant circuit at a cost $£ 5$ million. The filters will, it is claimed, reduce radiation doses to operators by 50 per cent.

This week, Friends of the Earth intends to raise the temperature of the proceedings by introducing a document produced by the UK Atomic Energy Authority but not publicly available in Britain. The document provisionally endorses a controversial study by the United States Oak Ridge National Laboratories which found actual rates of mishaps in reactors significantly in excess of predicted rates. Friends of the Earth says the document became available only because of an application in the United States under the Freedom of Information Act, and that the study of the frequency of mishaps at British reactors had been carried out under contract for a US customer.

If CEGB's application is granted, the result will be the introduction of a new type of reactor technology into Britain. The board's previous experience with building power stations is not encouraging, but it says that the PWR could be built in a record 19 months once it gets clearance. However, plans are already two years behind schedule and costs are rising.

Tim Beardsley

\title{
Can academic politics be banned?
}

\section{New Delhi}

INDIA'S University Grants Commission (UCG) has called on the ruling political parties in the central and state governments to "set an example" by refraining from interfering in the internal affairs of universities. At the same time, the commission urged academics and students to avoid bringing politics into university matters. Universities cannot be run effectively, Mrs Madhuri R. Shah, head of UGC, observed, while the present "free for all" is considered to be an expression of "democracy" in the universities.

Among those spheres of academic life which UGC considers should be free from "politics" are appointments, recruitment, admissions and some administrative and financial matters.

All these spheres have, of late, become imbued with politics. Thus a recent dispute over the appointment of a new vicechancellor at the University of Calcutta developed into a major confrontation (complete with students' strike) between the governor of West Bengal, Mr A.P. Sharma (who is ex officio chancellor of the university) and the Left Front state government. And a student campaign in Bangalore ostensibly demanding universal access to "scientific and democratic" higher education is closely linked with the conflict between the Janata state government and the Central Congress (I) government, and the opposition in southern India to Mrs Gandhi's hints that Hindi should replace English as India's "link language". In Assam, the All-Assam Students Union is allegedly involved in plans to bring down the state legislature.

UGC therefore suggests a formal separation of political and university life. Central and state ministers, it urges, should not seek appointment to university bodies, and university lecturers and employees who are elected to central or state legislative assemblies should be granted unpaid leave during their term of office.

University vice-chancellors should be given the "full trust" of government officials instead of, as often happens at present, the latter giving their overt or covert support to groups opposed to the university authorities. In the seven central universities (which are supported by the Delhi government), vice-chancellors should have direct access to the "highest quarters" of government, in recognition of their status as national institutions.

UGC does not spell out how these objectives might be attained, but simply appeals to the "maturity" of the political parties, calling on them to unite to save the universities "which have a key role in building the country's future". In the present atmosphere of tension between the central and state governments and the current militancy of Indian students, however, such exhortations seem somewhat utopian. 